OLIVEIRA, V.R.; CASALI, V.W.D.; CRUZ, C.D.; PEREIRA, P.R.G.; BRACCINI, A.L. Avaliação da diversidade genética em pimentão através de análise multivariada. Horticultura Brasileira, Brasília, v. 17, n. 1, p. 19-24, março 1999.

\title{
Avaliação da diversidade genética em pimentão através de análise multivariada.
}

\author{
Valter R. Oliveira ${ }^{1}$; Vicente Wagner D. Casali²; Cosme Damião Cruz ${ }^{3}$; Paulo Roberto G. Pereira ${ }^{2}$; \\ Alessandro de L. e Braccini ${ }^{4}$ \\ ${ }^{1}$ EPAMIG - Centro Tecnológico do Centro-Oeste, C. Postal 295, 35.701-970 Sete Lagoas - MG; ${ }^{2}$ UFV - Depto. de Fitotecnia; ${ }^{3}$ UFV - \\ Dep ${ }^{\text {to. }}$ de Biologia Geral, 36.571-000 Viçosa - MG; ${ }^{4}$ UEM - Dep ${ }^{\text {to. }}$ de Agronomia, 87.020-900 Maringá - PR.
}

\section{RESUMO}

A diversidade entre 133 genótipos de pimentão (Capsicum annuum L.), em relação a doze características agronômicas, foi avaliada através de técnicas de análise multivariada (distância $\mathrm{D}^{2}$ de Mahalanobis, agrupamento pelo método de Tocher e dispersão em eixos cartesianos). O ensaio foi conduzido no período de 6 de outubro de 1993 a 19 de março de 1994, em condições de campo, no município de Viçosa (MG), em solo Podzólico vermelho-amarelo câmbico. O delineamento experimental utilizado foi blocos completos casualizados, com três repetições, sendo cada parcela composta por seis plantas $\left(2,16 \mathrm{~m}^{2}\right)$. Com a metodologia utilizada foi observada a colocação dos genótipos em quinze grupos. Os genótipos P-141-195-F10, P-142-270-F10, P-14190-F13, cv. Apolo AG 511 e P-142-222-F13 destacaram-se pela diversidade e elevada produtividade (935 g/planta) e qualidade de frutos (frutos brilhantes, com formato cônico, de coloração verde-escura uniforme e com reduzida presença de deformações), o que os qualifica como promissores para serem utilizados em programas de melhoramento. As características com menor contribuição para a diversidade genética foram produção total de frutos por planta, número de dias para o início do florescimento, índice de concentração da colheita, diâmetro do caule e diâmetro do pedúnculo. As características de maior contribuição foram altura da primeira bifurcação, altura da planta, relação comprimento/largura do fruto e índice de precocidade

Palavras-chave: Capsicum annuum L., melhoramento, caracteristicas agronômicas, produção, análise de agrupamento, método de Tocher, indice de precocidade, indice de concentração da produção.

\begin{abstract}
Assessment of genetic diversity in sweet pepper using multivariate analysis.

Diversity among 133 sweet pepper (Capsicum annuum L.) genotypes in relation to twelve agronomic characteristics was assessed through multivariate analysis techniques (Mahalanobis' $\mathrm{D}^{2}$ distances, Tocher's cluster analysis, and dispersion graph analysis). The trial was carried out from October 6, 1993 to March 19, 1994, under field conditions, in Viçosa (MG), on a red yellow podzolic soil. The experimental design was a complete randomized block, with three replications, and each experimental plot was made up of six plants $\left(2.16 \mathrm{~m}^{2}\right)$. Through the analysis it was possible to cluster the sweet pepper genotypes in fifteen distinct groups. Genotypes P141-195-F10, P-142-270-F10, P-141-90-F13, cv. Apolo AG 511 and $\mathrm{P}-142-222-\mathrm{F} 13$ were the most divergent and showed the highest yields (935 g/plant) and fruit quality (bright, conical-shaped, uniformly dark green coloured fruits, with a reduced occurrence of deformations), which qualifies them as promising for genetic breeding programs. The characteristics that contributed less to genetic diversity were total yield per plant, number of days to begin flowering, index of cropping concentration, and stem and stalk diameter. Those with major contributions were firstly bifurcation and plant height, length/width ratio of fruits and index of earlyness.

Keywords: Capsicum annuum L., breeding, agronomic characteristics, yield, cluster analysis, Tocher 's method, index of earliness, index of cropping concentration.
\end{abstract}

\section{(Aceito para publicação em 21 de outubro de 1998)}

$E_{s}^{\text {n }}$ $\mathrm{m}$ programas de melhoramento baseados em hibridação, genótipos segregantes superiores são recuperados mais rápida e eficientemente quando a população-base para a seleção associa superioridade das características sob melhoramento à ampla variabilidade genética, esta última oriunda da diversidade genética entre os progenitores envolvidos nos cruzamentos (Falconer,
1981). Assim, o sucesso de um programa de melhoramento depende da escolha criteriosa dos progenitores a serem cruzados.

A diversidade genética pode ser observada pela quantificação da heterose manifestada nos cruzamentos ou por processos preditivos, que tomam por base as diferenças agronômicas, morfológicas e fisiológicas entre os genótipos e que não requerem a obtenção prévia das combinações híbridas. Estas combinações, em certas situações, são difíceis, como no caso de se dispor de um número elevado de genótipos para avaliação ou houver dificuldades nas práticas de hibridação artificial (Maluf et al., 1983; Miranda et al., 1988).

A seleção de progenitores com base em características individuais não é tão 
vantajosa quanto a seleção baseada em um conjunto de características, principalmente se o objetivo é o melhoramento de características quantitativas, como é o caso da produção. Quando diversas características são avaliadas simultaneamente, as distâncias genéticas relativas podem ser estimadas por procedimentos multivariados como a distância $\mathrm{D}^{2}$ de Mahalanobis, distância euclidiana, agrupamento pelo método de Tocher, variáveis canônicas, componentes principais e dispersão em eixos cartesianos, entre outros, sendo que a escolha do método é função da precisão desejada, da facilidade de análise e da forma de obtenção dos dados (Miranda et al., 1988; Cruz \& Regazzi, 1994; Cruz \& Viana, 1994). A vantagem dos métodos multivariados está no fato destes permitirem combinar as múltiplas informações contidas na unidade experimental, possibilitando a caracterização dos genótipos com base em um complexo de variáveis (Cruz \& Regazzi, 1994). A exemplo de outras espécies, técnicas multivariadas têm sido utilizadas para a quantificação da diversidade genética em pimentão (Capsicum annuum L.) (Miranda et al., 1988; Babu \& Varalakshmi, 1991; Moura, 1996).

Este trabalho teve como objetivo avaliar a diversidade de 133 genótipos de pimentão, com base em características agronômicas, por meio de procedimentos multivariados (distância $\mathrm{D}^{2} \mathrm{de}$ Mahalanobis, agrupamento pelo método de Tocher e dispersão em eixos cartesianos), para a seleção de progenitores a serem utilizados em futuros programas de melhoramento.

\section{MATERIAL E MÉTODOS}

Cento e vinte e oito linhagens, um acesso e quatro cultivares de pimentão da coleção de Capsicum do Banco de Germoplasma de Hortaliças da Universidade Federal de Viçosa (BGH-UFV) foram utilizados para o estudo da diversidade genética. As cultivares foram utilizadas como padrão para as características agronômicas.

O ensaio foi conduzido em condições de campo no município de Viçosa (MG), no período de 06 de outubro de 1993 a 19 de março de 1994, em solo
Podzólico vermelho-amarelo câmbico, fase terraço, de textura argilosa, com as seguintes características químicas: $\mathrm{pH}$ $5,3\left(\mathrm{em} \mathrm{H} \mathrm{H}_{2} \mathrm{O}\right) ; 8,2 \mathrm{mg} / \mathrm{dm}^{3}$ de $\mathrm{P} ; 84,0$ $\mathrm{mg} / \mathrm{dm}^{3}$ de $\mathrm{K}+; 2,5 \mathrm{cmolc} / \mathrm{dm}^{3}$ de $\mathrm{Ca} 2+$; $0,6 \mathrm{cmolc} / \mathrm{dm}^{3}$ de $\mathrm{Mg}_{2}+\mathrm{e} 0,2 \mathrm{cmolc} / \mathrm{dm}^{3}$ de $\mathrm{Al}^{3+}$.

As mudas foram preparadas em sementeira e transplantadas quando apresentavam, em média, cinco folhas definitivas. $\mathrm{O}$ solo foi adubado com $270 \mathrm{~kg}$ de $\mathrm{N}(60 \mathrm{~kg}$ no transplantio $+210 \mathrm{~kg}$ em cobertura), $30 \mathrm{~kg}$ de $\mathrm{P}_{2} \mathrm{O}_{5}(30+0)$, $170 \mathrm{~kg}$ de $\mathrm{K}_{2} \mathrm{O}(120+50), 72 \mathrm{~kg}$ de $\mathrm{Ca}$ $(72+0), 30 \mathrm{~kg}$ de $\mathrm{Mg}(30+0), 10 \mathrm{~kg}$ de $\mathrm{Zn}(10+0)$ e $3,5 \mathrm{~kg}$ de B $(3,5+0)$, por hectare, respectivamente, nas formas de nitrocálcio, superfosfato simples, cloreto de potássio, nitrocálcio, sulfato de magnésio, sulfato de zinco e bórax. Irrigações suplementares e demais tratos culturais, como capinas, tutoramento das plantas e controle fitossanitário foram efetuados na medida em que se fizeram necessários, de modo a manter as plantas sob condições ótimas de crescimento e desenvolvimento.

O delineamento experimental utilizado foi blocos completos casualizados, com três repetições. Cada parcela foi composta por uma fileira com seis plantas, espaçadas $0,40 \mathrm{~m}$, mantendo-se um espaçamento entre linhas de $0,90 \mathrm{~m}$. As características avaliadas foram: produção total de frutos (g/planta), com os frutos colhidos a intervalos médios de dez dias, quando apresentavam pelo menos o ápice com coloração avermelhada; índice de precocidade calculado pela equação IP $=a^{n}{ }_{i=1}\left(y_{i} / d_{1}\right)$, sendo $\mathrm{y}_{\mathrm{i}}=$ produção na i-ésima colheita, $d_{1}=$ número de dias do início ao final da i-ésima colheita e $\mathrm{n}=$ número de colheitas $(\mathrm{i}=1,2, \ldots, \mathrm{n})$ (Khanizadeh \& Fanous, 1992); índice de concentração da colheita calculado pela equação $\mathrm{CP}$ $=\left[a^{\mathrm{n}}{ }_{i=1}\left(\mathrm{p}_{1}-\mathrm{p}\right)^{2}\right]^{1 / 2}$, em que $\mathrm{p}_{\mathrm{i}}=$ porcentagem da produção total na i-ésima colheita, $p=$ produção percentual média para cada uma das $n$ colheitas e $n=$ número de colheitas $(i=1,2, \ldots, n)$ (Khanizadeh \& Fanous, 1992); peso médio de fruto $(\mathrm{g})$, pela razão entre o peso e o número total de frutos produzidos; relação entre o comprimento e a largura do fruto, com a largura medida na base do fruto; espessura da polpa (mm) da porção mediana do fruto; diâmetro do pedúnculo ( $\mathrm{mm}$ ) próximo à base do fruto; altura da planta $(\mathrm{cm})$, do nível do solo ao ponto mais alto da planta; altura da primeira bifurcação $(\mathrm{cm})$, a partir do nível do solo; diâmetro do caule (cm) próximo ao nível do solo; número de ramos na primeira bifurcação e número de dias para o início do florescimento, da semeadura até que $50 \%$ das plantas apresentassem pelo menos uma flor completamente aberta.

Em razão do grande número de genótipos avaliados, utilizaram-se duas estratégias no estudo da diversidade. $\mathrm{Na}$ primeira, avaliou-se a diversidade do conjunto dos 133 genótipos por meio da técnica de análise multivariada de agrupamento, pelo método de otimização de Tocher (Cruz \& Regazzi, 1994). Para a aplicação desta metodologia, inicialmente estimou-se a distância $\mathrm{D}^{2}$ de Mahalanobis, que é uma medida de dissimilaridade entre genótipos. Os genótipos foram, então, reunidos em grupos, cujo procedimento de análise mantém a distância média intragrupo inferior à qualquer distância média intergrupos. $\mathrm{O}$ valor médio máximo da distância intragrupo foi estabelecido como o valor máximo de $\mathrm{D}^{2}$ obtido no conjunto de menores distâncias envolvendo cada genótipo. Na segunda estratégia, utilizou-se a metodologia de análise proposta por Cruz et al. (1991), que permite o estudo da diversidade genética por meio da dispersão dos genótipos em sistemas de coordenadas, mesmo quando se dispõe de um elevado número.

Os 133 genótipos (grupo original) foram divididos em nove subgrupos, segundo a produção de frutos por planta e a relação comprimento/largura do fruto, que são duas características economicamente importantes. Para a formação dos nove subgrupos, os genótipos foram divididos, quanto à produção total de frutos por planta (PT), nas classes alta (genótipos com PT ${ }^{3} 935 \mathrm{~g}$ ), média $(720 £ \mathrm{PT}<935$ g) e baixa (PT $<720$ g), e, quanto à relação comprimento/largura do fruto (RCL), nas classes comprido $\left(\mathrm{RCL}^{3} 1,7\right)$, intermediário $(1,5 £$ $\mathrm{RCL}<1,7)$ e curto $(\mathrm{RCL}<1,5)$. Pela combinação das classes das duas características consideradas, estabeleceramse os nove subgrupos, designados por 
$\mathrm{G}_{\mathrm{ij}}(\mathrm{i}, \mathrm{j}=1,2,3)$. O subgrupo G11, denominado elite, constituído de genótipos com alta produção por planta e frutos compridos, foi submetido à análise de agrupamento pelo método de Tocher, utilizando-se as distâncias $\mathrm{D}^{2}$ de Mahalanobis. Adicionalmente, a diversidade entre os genótipos do grupo elite foi avaliada e representada em gráfico de dispersão, conforme metodologia proposta por Cruz \& Viana (1994). As coordenadas de cada genótipo foram estimadas a partir da matriz de dissimilaridade, adotando-se o critério de minimizar as diferenças entre as distâncias originais e as distâncias no espaço bidimensional. Também foram estimadas as distâncias $\mathrm{D}^{2}$ entre o subgrupo elite $\mathrm{e}$ os demais subgrupos considerados.

A contribuição relativa de cada característica para a diversidade entre os genótipos foi avaliada pela metodologia descrita por Singh (1981), que se baseia na partição do total das estimativas das distâncias $\mathrm{D}^{2}$ de Mahalanobis, considerando todos os possíveis pares de indivíduos, para as partes devida a cada característica. Esta contribuição foi avaliada pelo valor de $\mathrm{S}_{\mathrm{j}}$. Todas as análises foram realizadas com o auxílio do programa computacional Genes (Cruz, 1997).

\section{RESULTADOS E DISCUSSÃO}

Houve diferenças significativas entre as médias dos genótipos para todas as características (teste $\mathrm{F}, \mathrm{P}<0,01$ ). $\mathrm{O}$ rendimento, com base na produção total de frutos por planta, apresentou variação superior a $100 \%$, destacando-se 35 genótipos (Tabela 1) como mais produtivos (teste de Scott-Knott, $\mathrm{P}<0,01$ ). Estes genótipos apresentaram média de produtividade entre 935,0 e 1143,3 g/ planta, igual ou superior à das cultivares, que situou-se entre 860,4 e 1005,0 g/planta. Todos os 133 genótipos apresentaram frutos com formato cônico, de coloração verde-escura uniforme e brilhante, com reduzida presença de deformações, mas variáveis quanto à relação comprimento/largura do fruto $(1,2-2,5)$, peso médio $(30,9-74,0 \mathrm{~g})$ e espessura de polpa $(3,2-5,0 \mathrm{~mm})$. Em relação à precocidade, os genótipos mostraram comportamento divergente, destacandose como mais precoces, entre os mais
Tabela 1. Produção total de frutos por planta (PROD), relação entre o comprimento e a largura do fruto (RCL), peso médio de fruto (PMF), índice de precocidade (IP), espessura da polpa (EP) e altura da planta (AP), dos 35 genótipos de pimentão mais produtivos e das quatro cultivares-padrão. Viçosa, UFV, 1994.

\begin{tabular}{|c|c|c|c|c|c|c|}
\hline Genótipos & $\begin{array}{c}\text { Prod } \\
\text { (g/planta) }\end{array}$ & RCL & PMF (g) & IP & $\mathbf{E P}(\mathbf{m m})$ & $\mathbf{A P}(\mathbf{c m})$ \\
\hline P-141-27-F13 & 1034,2 & 1,7 & 59,0 & 24,5 & 4,8 & 82,2 \\
\hline P-141-29-F8 & 1088,8 & 1,7 & 68,0 & 17,0 & 4,7 & 75,5 \\
\hline P-141-90-F13 & 1030,8 & 2,3 & 54,5 & 7,0 & 4,2 & 63,4 \\
\hline P-141-102-F13 & 963,8 & 1,7 & 49,0 & 26,6 & 4,0 & 70,6 \\
\hline P-141-157-F13 & 974,6 & 2,1 & 47,6 & 23,7 & 4,0 & 64,1 \\
\hline P-141-164-F7 & 1131,3 & 1,3 & 61,5 & 21,5 & 4,2 & 71,9 \\
\hline P-141-177-F7 & 1143,3 & 1,9 & 67,5 & 10,6 & 4,7 & 73,6 \\
\hline P-141-191-F14 & 982,5 & 1,4 & 55,1 & 28,5 & 4,6 & 75,9 \\
\hline P-141-195-F10 & 959,6 & 2,0 & 44,7 & 8,4 & 3,9 & 105,5 \\
\hline P-142-222-F13 & 983,8 & 1,8 & 54,0 & 35,0 & 4,5 & 86,3 \\
\hline P-142-224-F13 & 946,7 & 1,6 & 48,0 & 7,9 & 4,2 & 89,7 \\
\hline P-142-233-F5 & 1006,3 & 1,5 & 60,2 & 10,7 & 4,5 & 79,9 \\
\hline P-142-236-F13 & 943,8 & 2,0 & 59,8 & 24,5 & 4,2 & 77,9 \\
\hline P-142-256-F12 & 1111,7 & 1,5 & 57,8 & 39,0 & 4,0 & 77,4 \\
\hline P-142-270-F10 & 993,3 & 2,5 & 55,7 & 13,0 & 4,2 & 91,7 \\
\hline P-142-284-F8 & 1062,5 & 1,5 & 60,4 & 24,5 & 4,7 & 75,7 \\
\hline P-142-292-F10 & 1004,6 & 1,6 & 59,6 & 9,2 & 4,0 & 91,9 \\
\hline P-142-309-F13 & 1072,9 & 1,7 & 66,7 & 12,4 & 4,6 & 84,3 \\
\hline P-142-314-F9 & 1107,1 & 1,5 & 47,5 & 32,8 & 4,3 & 79,1 \\
\hline P-142-319-F7 & 982,9 & 1,3 & 54,9 & 9,3 & 4,2 & 92,8 \\
\hline P-142-325-F13 & 1026,3 & 1,5 & 47,0 & 9,7 & 4,1 & 84,1 \\
\hline P-142-328-F12 & 1054,2 & 1,5 & 59,5 & 38,3 & 4,6 & 70,7 \\
\hline P-142-334-F13 & 943,8 & 1,4 & 59,7 & 14,3 & 4,7 & 80,3 \\
\hline P-142-344-F13 & 1094,2 & 1,4 & 57,6 & 29,0 & 4,2 & 75,4 \\
\hline P-142-347-F5 & 1042,7 & 1,7 & 48,1 & 13,8 & 4,0 & 86,3 \\
\hline P-142-349-F13 & 983,8 & 1,9 & 38,0 & 18,8 & 3,7 & 71,1 \\
\hline P-142-352-F13 & 1001,7 & 1,2 & 69,6 & 30,4 & 4,5 & 70,7 \\
\hline P-142-353-F13 & 998,3 & 1,8 & 50,5 & 16,1 & 4,1 & 78,8 \\
\hline P-142-356-F9 & 936,7 & 1,7 & 52,5 & 7,0 & 4,0 & 80,4 \\
\hline P-142-359-F9 & 994,6 & 1,5 & 47,9 & 14,0 & 4,0 & 75,2 \\
\hline P-142-367-F7 & 935,0 & 1,9 & 54,8 & 9,4 & 4,0 & 78,3 \\
\hline P-142-371-F10 & 952,5 & 1,6 & 57,0 & 8,7 & 4,3 & 86,9 \\
\hline P-142-378-F10 & 988,8 & 2,2 & 52,3 & 25,5 & 4,0 & 78,4 \\
\hline P-142-403-F9 & 1000,0 & 1,8 & 53,8 & 8,8 & 4,7 & 83,0 \\
\hline BGH 3623 & 1004,6 & 1,5 & 61,3 & 9,3 & 4,5 & 88,4 \\
\hline Apolo AG 511 & 1005,0 & 2,0 & 62,5 & 9,4 & 4,6 & 105,9 \\
\hline Cascadura Ikeda & 910,2 & 1,7 & 47,8 & 8,9 & 4,0 & 108,7 \\
\hline Hércules AG 672 & 900,8 & 1,7 & 59,8 & 25,6 & 4,1 & 96,1 \\
\hline Magda & 860,4 & 1,6 & 64,9 & 9,8 & 4,0 & 100,2 \\
\hline
\end{tabular}


produtivos, os genótipos P-142-256F12, P-142-328-F12, P-142-222-F13, P142-314-F9, P-142-352-F13, P-142344-F13, P-141-191-F14, P-141-102F13 e P-142-378-F10 e, como mais tardios, os genótipos P-142-356-F9, P-14190-F13, P-142-224-F13, P-141-195F10, P-142-371-F10, P-142-403-F9, P142-292-F10, BGH 3623, P-142-319. F7 e P-142-367-F7.

Observaram-se diferenças significativas entre os genótipos, com relação à altura da planta, destacando-se como os mais altos ( $\mathrm{AP}^{3} 80 \mathrm{~cm}$ ), entre os mais produtivos, os genótipos P-141-195F10, P-142-319-F7, P-142-292-F10, P142-270-F10, P-142-224-F13, BGH 3623, P-142-371-F10, P-142-222-F13, P-142-347-F5, P-142-309-F13, P-142325-F13, P-142-403-F9 e P-141-27-F13 e, como os mais baixos (AP $£ 65 \mathrm{~cm}$ ), os genótipos P-141-90-F13 e P-141157-F13. Os demais genótipos apresentaram altura entre 70 e $80 \mathrm{~cm}$. Verificou-se que os genótipos mais produtivos apresentaram porte médio a alto, o que está de acordo com a correlação positiva e significativa $(r=0,56$, $\mathrm{P}<0,01$ ) observada entre altura da planta e produção total de frutos por planta e confirma os resultados obtidos por Braz (1982).

Segundo a distância $\mathrm{D}^{2} \mathrm{de}$ Mahalanobis, considerando as doze características agronômicas avaliadas, o par de genótipos P-142-339-F13 e P142-347-F5 apresentou a menor distância genética $(4,17)$, enquanto o par P141-4-F10 e 'Cascadura Ikeda', apresentou a maior distância genética $(357,40)$. Analisando no sentido da maior distância média em relação ao conjunto de genótipos, destacou-se a cultivar Cascadura Ikeda, com $\mathrm{D}^{2}$ médio $(159,08)$ superior à média das distâncias considerando todos os pares de genótipos, igual a 56,43.

O reconhecimento de grupos de genótipos com elevada similaridade pela observação do conjunto de distâncias é trabalhoso e pouco eficiente, devido ao elevado número de medidas disponíveis (8778). Deste modo, métodos que, por algum critério de classificação, reúnam genótipos em grupos homogêneos são importantes na seleção dos melhores progenitores. A partição do conjunto de genótipos em grupos de similaridade pelo método de otimização de Tocher, com base nas distâncias D2 de Mahalanobis, tem como princípio básico tornar a distância $\mathrm{D}^{2}$ mínima dentro e, máxima, entre grupos. Por meio deste método, observou-se a formação de quinze grupos, destacando-se um grupo com 79 genótipos $(59,40 \%$ do total de genótipos avaliados) e outros seis grupos constituídos por apenas um genótipo cada. Este padrão de distribuição, com concentração de indivíduos em um grupo e os demais dispersos em grupos diversos, evidencia a ampla diversidade dos genótipos. Pela disposição em grupos unitários e consequentemente, pela dissimilaridade entre si e em relação ao conjunto como um todo, destacaram-se os genótipos Apolo AG 511, P-142-270-F10, P-141185-F9, P-142-264-F7, P-142-352-F13 e P-141-146-F9.

Embora a técnica de agrupamento minimize a variabilidade dentro do grupo, a estimativa de distâncias de elevada magnitude entre pares de indivíduos do grupo que apresentou 79 genótipos, como, entre os genótipos P-141-104F10 e P-142-371-F10 (D $=80,08)$, indica que acentuada variabilidade dentro deste grupo ainda permanece, e que, justifica-se então, o reagrupamento. Procedeu-se então à redistribuição dos indivíduos do grupo, estabelecendo-se 20 subgrupos, de onde destacaram-se seis, constituídos por apenas um genótipo cada. Pela disposição em grupos unitários, e, por conseguinte, pela dissimilaridade entre si e em relação aos demais indivíduos do grande grupo, destacaram-se os genótipos P-141-179-F7, P-142-367-F7, P-141-206-F13, P-142-214-F13, P-142322-F7 e P-142-238-F13.

A técnica de agrupamento, embora eficiente no estabelecimento de grupos de similaridade, não possibilita reconhecer a distância entre indivíduos de um mesmo grupo ou entre indivíduos de grupos distintos, sem que se recorra ao conjunto de distâncias genéticas estimadas, uma vez que com o agrupamento, as informações a nível de indivíduos são perdidas, restando apenas as médias dos grupos. Deste modo, é prática comum complementar a análise de agrupamento com a dispersão em sistema de eixos cartesianos, em que a posição relativa dos genótipos possa ser visualizada. Este procedimento torna-se mais importante na medida em que diferentes técnicas de estudo da diversidade genética podem levar a diferentes padrões de similaridade (Cruz \& Regazzi, 1994). No caso presente, o grande número de genótipos torna ineficiente a utilização deste procedimento, devido à dificuldade de identificação dos indivíduos no gráfico de dispersão. Neste aspecto, Cruz et al. (1991) sugerem, como estratégia de análise, a divisão do conjunto original de genótipos em vários subgrupos, um dos quais é considerado elite, por reunir aqueles de maior interesse para programas de melhoramento, ou seja, aqueles com qualidades agronômicas superiores. Assim, dividiu-se o conjunto original de genótipos em nove subgrupos segundo a produção de frutos por planta e a relação comprimento/largura do fruto.

A composição dos nove subgrupos variou de seis (subgrupo $\mathrm{G}_{12}$ : genótipos com alta produção e frutos intermediários) a 29 genótipos (subgrupo $\mathrm{G}_{22}$ : genótipos com produção média e frutos intermediários). O subgrupo elite concentrou quinze genótipos (P-141-27F13, P-141-29-F8, P-141-90-F13, P141-102-F13, P-141-157-F13, P-141177-F7, P-141-195-F10, P-142-222F13, P-142-236-F13, P-142-270-F10, P142-349-F13, P-142-353-F13, P-142378-F10, P-142-403-F9 e 'Apolo AG.511'), ou seja, $11,28 \%$ do total de genótipos avaliados. Verificou-se que a maioria dos 35 genótipos citados anteriormente como mais produtivos (Tabela 1) não foi classificada como elite, porque seus frutos não se enquadraram no padrão de relação comprimento/largura estabelecido para o grupo elite. Isto não significa, no entanto, que esses genótipos estejam desqualificados para futuros programas de melhoramento. Deve-se lembrar que a inclusão de um indivíduo em uma determinada classe é baseada em valor numérico, o que na prática, pode reduzir sua importância à medida em que outros atributos, como cor, brilho, peso médio, espessura de polpa, entre outros, sejam considerados na avaliação.

A média das distâncias, considerando todos os pares de genótipos do 
subgrupo elite, em relação às doze características agronômicas avaliadas, com base na distância $\mathrm{D}^{2}$ de Mahalanobis foi de 55,80. A distância mínima observada foi de 10,26 entre os genótipos P-141-29-F8 e P-141-177-F7, e, a máxima, de 167,20, entre os genótipos P-141-90-F13 e P-141-195F10. Outros pares de genótipos que se destacaram pelas suas grandes distâncias foram P-141-29-F8 e P-141-195F10 (D2=137,92), P-141-177-F7 e P141-195-F10 (131,56), P-141-102-F13 e P-141-195-F10 (128,52), P-141-102F13 e P-142-270-F10 (122,89), P-142222-F13 e P-141-195-F10 (122,72), P142-222-F13 e P-142-270-F10 $(121,89)$ e P-141-90-F13 e 'Apolo AG 511' $(115,57)$ e, pelas pequenas distâncias, os pares P-142-236-F13 e P-142-378-F10 $(11,84), \mathrm{P}-141-157-\mathrm{F} 13$ e P-142-349F13 (11,97), P-141-102-F13 e P-142353-F13 $(12,85)$ e P-141-27-F13 e P141-29-F8 (13,04). Analisando no sentido da maior distância média em relação ao restante do subgrupo, destacouse a linhagem P-141-195-F10, com média igual a 99,38 .

A interpretação da diversidade dos genótipos do subgrupo elite, a partir do agrupamento pelo método de Tocher e dispersão gráfica em sistemas de coordenadas são concordantes. Os genótipos mais divergentes em relação ao conjunto, foram P-141-195-F10, P-142-270F10, P-141-90-F13, 'Apolo AG 511' e P-142-222-F13 (Figura 1). O posicionamento espacial das linhagens P-141-29-F8 e P-141-177-F7 também está coerente com a pequena distância observada para este par de genótipos. Esta coerência certamente está associada ao pequeno grau de distorção $(6,98 \%)$ e à alta correlação $(\mathrm{r}=0,91, \mathrm{P}<0,01)$ entre as distâncias estimadas das coordenadas e as distâncias originais, que são medidas da eficiência da projeção das distâncias em um espaço bidimensional (Cruz \& Viana, 1994). Observou-se que mesmo restringindo o estudo aos genótipos do subgrupo elite, ampla variabilidade genética ainda permaneceu. Isto é importante, uma vez que maiores chances de sucesso no melhoramento são esperadas pela combinação de genótipos superiores e mais distantes geneticamente, porém portadores de

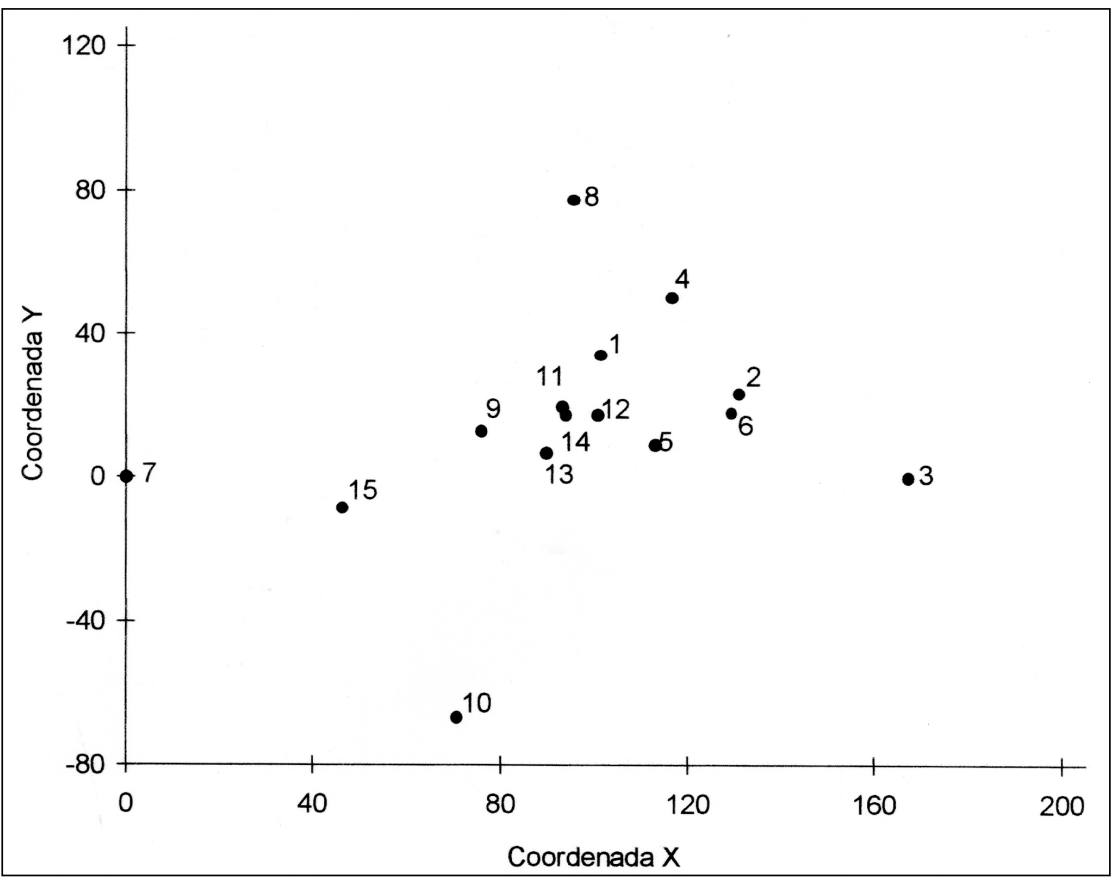

Figura 1. Dispersão de quinze genótipos de pimentão do subgrupo-elite usando as coordenadas obtidas da matriz de distâncias $\mathrm{D}^{2}$, pelo procedimento estatístico baseado na minimização das diferenças entre as distâncias originais e aquelas no gráfico. Viçosa, UFV, 1994.

Genótipos: 1 = P-141-27-F13, 2 = P-141-29-F8, 3 = P-141-90-F13, 4 = P-141-102-F13, 5 = P-141-157-F13, 6 = P-141-177-F7, 7 = P-141-195-F10, 8 = P-142-222-F13, 9 = P-142-236F13, 10 = P-142-270-F10, 11 = P-142-349-F13, 12 = P-142-353-F13, 13 = P-142-378-F10, 14 = P-142-403-F9, 15 = 'Apolo AG 511'.

complementação alélica para determinadas características.

É importante analisar a dissimilaridade genética entre os genótipos componentes do subgrupo elite e os pertencentes aos demais subgrupos, por meio da distância $\mathrm{D}^{2}$ que separa estes subgrupos. A menor distância estabelecida foi em relação a $G_{12}$ : genótipos com alta produção e frutos intermediários $(48,83)$, seguida de $\mathrm{G}_{21}$ : genótipos com produção média e frutos compridos $(56,21), \mathrm{G}_{31}$ : genótipos com baixa produção e frutos compridos $(61,42), \mathrm{G}_{22}$ : genótipos com produção média e frutos intermediários $(64,32)$, $\mathrm{G}_{32}$ : genótipos com baixa produção e frutos intermediários $(66,15), \mathrm{G}_{13}$ : genótipos com alta produção e frutos curtos $(68,73), \mathrm{G}_{33}$ : genótipos com baixa produção e frutos curtos $(79,99) \mathrm{e}$ $\mathrm{G}_{23}$ : genótipos com produção média e frutos curtos $(80,08)$. Concluiu-se, portanto, que a diversidade do subgrupo elite em relação aos demais foi devida basicamente à produção total e à relação comprimento/largura dos frutos adotadas para estabelecimento dos subgrupos. Por conseguinte, em relação às demais características, os subgrupos foram constituídos por amostras aleatórias do conjunto original.

As características mais importantes para a diversidade foram as responsáveis pelas maiores distâncias $\mathrm{D}^{2}$ estimadas para os pares de genótipos. Constatou-se que, no grupo original (133 genótipos) e no grupo composto pelos 79 genótipos, as cinco características com menor contribuição relativa para a distância total foram produção total de frutos por planta, número de dias para o início do florescimento, diâmetro do pedúnculo, diâmetro do caule e índice de concentração da colheita, enquanto no subgrupo elite, as características com menor contribuição relativa para a distância total foram produção total de frutos por planta, índice de concentração da colheita, diâmetro do caule, número de dias para o início do florescimento e diâmetro do pedúnculo (Tabela 2). Estas características apresentaram os menores valores da estatística $F$, determinados pela razão entre o quadrado médio para o efeito de genótipos e aquele 
Tabela 2. Contribuição relativa de cada característica para a diversidade entre os indivíduos componentes do grupo com 133 genótipos $\left(\mathrm{Grupo}_{133}\right)$, grupo com 79 genótipos $\left(\mathrm{Grupo}_{79}\right)$ e subgrupo-elite (genótipos com alta produção por planta e frutos compridos), com base nos valores de S. Viçosa, UFV, 1994

\begin{tabular}{lcrrrrr}
\hline \multicolumn{1}{c}{ Caracteristicas } & \multicolumn{2}{c}{ Grupo $_{\mathbf{1 3 3}}$} & \multicolumn{2}{c}{ Grupo $_{\mathbf{7 9}}$} & \multicolumn{2}{c}{ Subgrupo elite $^{-}$} \\
\hline & $\mathbf{S j}$ & $\boldsymbol{\%}$ & $\mathbf{S j}$ & $\boldsymbol{\%}$ & $\mathbf{S j}$ & $\mathbf{\%}$ \\
Altura da planta & 56906,6 & 11,5 & 12295,9 & 12,2 & 897,1 & 15,2 \\
Altura da primeira bifurcação & 86644,1 & 17,5 & 12466,7 & 12,4 & 1342,4 & 22,7 \\
Dias para o florescimento & 12448,4 & 2,5 & 4082,8 & 4,1 & 222,4 & 3,8 \\
Diâmetro do caule & 20322,3 & 4,1 & 5548,1 & 5,5 & 221,7 & 3,8 \\
Diâmetro do pedúnculo & 19099,6 & 3,9 & 5705,9 & 5,7 & 289,6 & 4,9 \\
Espessura de polpa & 29614,9 & 6,0 & 11656,6 & 11,6 & 346,2 & 5,9 \\
Número de ramos & 33193,0 & 6,7 & 7969,9 & 7,9 & 312,3 & 5,3 \\
Peso médio de fruto & 33934,5 & 6,9 & 9520,0 & 9,5 & 459,2 & 7,8 \\
Produção total frutos/planta & 12119,8 & 2,5 & 4106,3 & 4,1 & 25,1 & 0,4 \\
Relação comprimento/largura & 72647,3 & 14,7 & 10248,7 & 10,2 & 881,6 & 14,9 \\
Índice de concentração da colheita & 21810,3 & 4,4 & 4755,7 & 4,7 & 171,5 & 2,9 \\
Índice de precocidade & 96619,1 & 19,5 & 12228,6 & 12,2 & 740,2 & 12,5 \\
\hline
\end{tabular}

referente ao resíduo. Em contrapartida, altura da primeira bifurcação, altura da planta, relação comprimento/largura do fruto e índice de precocidade, com as maiores contribuições para o total de $\mathrm{D}^{2}$, foram as características de maior importância para a caracterização da variabilidade em ambos os grupos.

Uma boa estratégia para a escolha de progenitores em programas de hibridação é considerar não apenas a diversidade genética, mas também o desempenho dos progenitores. Logo, os genótipos divergentes do subgrupo elite são, particularmente, interessantes, pois a população deles obtida deve apresentar superioridade e variabilidade. Por outro lado, a elevada similaridade manifestada entre os genótipos sugere que estes poderiam não ser incluídos em avaliações futuras ou evitados em cruzamentos. Da mesma forma, o número de dias para o início do florescimento, índice de concentração da colheita, diâmetro do caule e diâmetro do pedúnculo, pela pequena variação manifestada entre os genótipos, poderiam ser desconsideradas em avaliações futuras, dando-se ênfase apenas às características com informações agronômicas mais relevantes.

\section{LITERATURA CITADA}

BABU, H.K.; VARALAKSHMI, B. Genetic divergence, heritability and genetic advance in chilli (Capsicum annuum L.). Indian Journal of Genetic and Plant Breeding, v. 51, n. 2, p. $174-178,1991$.

BRAZ, L.T. Avaliação de caracteres agronômicos e qualitativos de três cultivares de pimentão (Capsicum annuum L.) e da heterose em seus híbridos F1. Viçosa: UFV, 1982. 75 p. (Tese mestrado).

CRUZ, C.D. Programa Genes. Aplicativo computacional em genética e estatística. Viçosa: Editora UFV, 1997. 442 p.

CRUZ, C.D.; PEREIRA, A.V.; VENCOVSKY, R.A. A proposal for analysis of genetic divergence among germplasm bank acessions. Revista Brasileira de Genética, Ribeirão Preto, v. 14, n. 4, p. 991 - 999, 1991.

CRUZ, C.D.; REGAZZI, A.J. Modelos biométricos aplicados ao melhoramento genético. Viçosa: Imprensa Universitária, 1994. $390 \mathrm{p}$.

CRUZ, C.D.; VIANA, J.M.S. A methodology of genetic divergence analysis based on sample unit projection on two-dimensional space. Revista Brasileira de Genética, Ribeirão Preto, v. 17, n. 1, p. 69 - 73, 1994

FALCONER, D.S. Introduction to quantitative genetics. 2. ed. London: Longman, 1981. $340 \mathrm{p}$.

KHANIZADEH, S.; FANOUS, M.A Mathematical indices for comparing small fruit crops for harvest time and trait similarity. HortScience, v. 27, n. 4, p. 346 348, 1992.
MALUF, W.R.; FERREIRA, P.E.; MIRANDA, J.E.C. de. Genetic divergence in tomatoes and its relationship with heterosis for yield in F1 hybrids. Revista Brasileira de Genética, Ribeirão Preto, v. 6, n. 3, p. 453 - 460, 1983

MIRANDA, J.E.C. de; CRUZ, C.D.; COSTA, C.P. da. Predição de comportamento de híbridos de pimentão (Capsicum annuum L.) pela divergência genética dos progenitores. Revista Brasileira de Genética, Ribeirão Preto, v. 11, n. 4, p. 929 - 937, 1988.

MOURA, W.M. Eficiência nutricional para fósforo em linhagens de pimentão (Capsicum annuum L.). Viçosa: UFV, 1996. 102 p. (Tese doutorado)

SINGH, D. The relative importance of characters affecting genetic divergence. Indian Journal of Genetic and Plant Breeding, v. 41, n. 2, p. 237 - 245, 1981. 